\title{
A Nova Contabilidade Aplicada ao Setor Público: uma análise nos municípios do COREDE-FO ${ }^{1}$
}

\author{
Brazilian Public Accounting: an analysis in the municipalities of COREDE-FO
}

\section{La Nueva Contabilidad Aplicada al Sector Público: un análisis en los municipios del COREDE-FO}

\begin{abstract}
Reginara Oliveira Macedonio Vega, Graduada em Tecnologia em Gestão Pública pela Universidade Federal do Pampa (UNIPAMPA). Endereço Profissional: Universidade Federal do Pampa (UNIPAMPA), Campus Santana do Livramento. Rua Barão do Triunfo, 1048, Santana do Livramento, RS, Brasil, CEP 97573634. Telefone: (55) 32434540. URL da Homepage: http://porteiras.unipampa.edu.br/livramento/. E-mail: rom_vegas@hotmail.com
\end{abstract}

Jeferson Luís Lopes Goularte, Doutorando em Ciencias de la Educación pela Universidad Nacional de Rosario (UNR), Argentina. Endereço Profissional: Universidade Federal do Pampa (UNIPAMPA), Campus Santana do Livramento. Rua Barão do Triunfo, 1048, Santana do Livramento, RS, Brasil, CEP 97573634. Telefone: (55) 32434540. URL da Homepage: http://porteiras.unipampa.edu.br/livramento/. E-mail: jefersongoularte@unipampa.edu.br

Camila Furlan da Costa, Doutoranda em Administração pela Universidade Federal do Rio Grande do Sul (UFRGS). Endereço Profissional: Universidade Federal do Pampa (UNIPAMPA), Campus Santana do Livramento. Rua Barão do Triunfo, 1048, Santana do Livramento, RS, Brasil, CEP 97573634. Telefone: (55) 32434540. URL da Homepage: http://porteiras.unipampa.edu.br/livramento/. E-mail: camilacosta@ unipampa.edu.br

Ariel Behr, Doutor em Administração pela Universidade Federal do Rio Grande do Sul (UFRGS). Endereço Profissional: Universidade Federal do Rio Grande do Sul, Faculdade de Ciências Econômicas, Departamento de Ciências Contábeis e Atuariais, Av. João Pessoa, 52, Porto Alegre, RS, Brasil, CEP 90040000. Telefone: (51) 33083487. URL da Homepage: http://www.ufrgs.br/fce/ensino/graduacao/. E-mail: $\underline{\text { ariel.behr@ufrgs.br }}$

Thadeu José Francisco Ramos, Mestre em Administração pela Universidade Federal do Rio Grande do Sul (UFRGS). Endereço Profissional: Universidade Federal do Pampa (UNIPAMPA), Campus Santana do Livramento. Rua Barão do Triunfo, 1048, Santana do Livramento, RS, Brasil, CEP 97573634. Telefone: (55) 32434540. URL da Homepage: http://porteiras.unipampa.edu.br/livramento/. E-mail: thadeuramos@unipampa.edu.br

\footnotetext{
${ }^{1}$ Artigo submetido em 28/02/2014, aceito em 16/03/2015 e divulgado em 31/12/2015 pelo Editor João Carlos Hipólito Bernardes do Nascimento, após double blind review.

GєECont, v.2, n. 2, Floriano-PI, Jul-Dez. 2015.
} 


\section{RESUMO}

A Contabilidade Aplicada ao Setor Público (CASP) tem como desafio implementar as Normas Brasileiras de Contabilidade Aplicadas ao Setor Público (NBCASP), a partir da convergência as International Public Sector Accounting Standards (IPSAS). Esta pesquisa tem por objetivo analisar a implementação da Contabilidade Aplicada ao Setor Público (CASP), abrangendo as Normas de Contabilidade Aplicada no Setor Público (NBCASP), o Plano de Contas Aplicada no Setor Público (PCASP) e as Demonstrações Contábeis Aplicadas no Setor Público (DCASP). A pesquisa caracteriza-se como descritiva e qualitativa. Os instrumentos de coleta de dados foram a análise documental e o questionário que foi enviado por meio de correio eletrônico aos municípios do Conselho Regional de Desenvolvimento da Fronteira Oeste (COREDE-FO), no Estado do Rio Grande do Sul. Os resultados da pesquisa evidenciam que os respondentes possuem conhecimento sobre o processo de convergência, que essas mudanças contribuem no aumento da transparência na aplicação dos recursos e gestão do patrimônio nos municípios e contribuem para o processo de tomada de decisões dos gestores públicos. Evidencia-se uma preocupação por parte dos profissionais em relação a implementação das NBCASP e do plano de contas de padrão único que tem dependência dos sistemas de informação, além da capacitação e treinamento dos servidores. Ainda é evidenciada a importância das Demonstrações Contábeis para transparência à população, entretanto, a linguagem das informações pode não ser clara a toda população.

Palavras-chave: Contabilidade Aplicada ao Setor Público; Normas Brasileiras de Contabilidade Aplicada ao Setor Público; Plano de Contas Aplicado ao Setor Público.

\section{ABSTRACT}

Public Sector Applied Accounting (CASP) is challenged to implement the Brazilian Accounting Standards Applied to the Public Sector (NBCASP) from the convergence to International Public Sector Accounting Standards (IPSAS). This research aims to analyze the implementation of CASP, covering the NBCASP, the Public Sector Applied Accounting Plan (PCASP) and the Financial Statements Applied to Public Sector (DCASP). The research is characterized as descriptive and qualitative study. The data collection instruments were performed by a document analysis and a electronic mail survey applied thought the municipalities of the Regional Council of West Frontier Development (COREDE-FO) in state of "Rio Grande do Sul". The results shows that respondents have knowledge about the process of convergence, that these changes contribute to increased transparency in the application of resources and municipalities heritage management, and contribute to the decision-making process of public managers. We can see a concern by professionals regarding the implementation of NBCASP and PCASP with unique pattern which depends on information systems, as well as training and qualification of workers. Furthermore, we highlight the importance of the Financial Statements for transparency to this population, however the language of the information may not be clear to the whole population.

Keywords: Public Sector Applied Accounting; Brazilian Accounting Standards Applied to the Public Sector; Public Sector Applied Accounting Plan.

\section{RESUMEN}

La Contabilidad Aplicada al Sector Público tiene como desafío implementar las Normas Brasileñas de Contabilidad Aplicadas al Sector Público (NBCASP), el modelo vigente exigido 
por la convergencia a las Normas Internacionales de Contabilidad Aplicada al Sector Público (IPSAS). Los objetivos de la presente investigación es de identificar las Normas Brasileñas de Contabilidad Aplicadas al Sector Público, en un segundo momento, identificar la estructura del Plan de Cuentas Aplicadas en el Sector Público (PCASP) y de las Demostraciones Contables Aplicadas en el Sector Público (DCASP), y, por último, comprobar el desarrollo de NBCASP, el PCASP, y DCASP en los municipios del COREDEFO (Consejo Regional de Desarrollo de la Frontera Oeste). La investigación se caracteriza como: social aplicada, exploratoria, descriptiva y cualitativa. El instrumento de coleta fue a través de cuestionarios y el mismo fue aplicado por medio de correo electrónico. Los resultados obtenidos por medio de las respuestas de los profesionales del área contable de las Intendencias evidencian un posicionamiento positivo con respecto a la aplicación de las NBCASP, cabe al administrador público proporcionar las herramientas que contribuyan para la aplicación de los mismos. Las limitaciones encontradas para la realización de la presente pesquisa no fueron un impedimento para que el análisis se desarrollara y demostrara como se encuentran las organizaciones Públicas frente a los cambios introducidos por NBCASP.

Palabras-clave: Contabilidad, Normas Brasileñas, Plan de cuentas, Demostraciones Contables.

\section{Introdução}

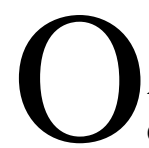

gestor público como autoridade dentro do Poder Público tem a Contabilidade Aplicada ao Setor Público (CASP) como uma aliada nas tomadas de decisões com informações consistentes e tempestivas, em todos os entes da federação, ou seja, nos Municípios, Estados, Distrito Federal e União. A Contabilidade Aplicada ao Setor Público (CASP) como fonte de informação detém os atos e fatos administrativos em registros contábeis de uma entidade pública, em relação a gestão orçamentária, financeira e patrimonial.

Nas tomadas de decisões é imprescindível que as demonstrações contábeis obtenham consistência e transparência na sua elaboração. Neste sentido, as demonstrações contábeis apresentam, segundo Lima e Castro (2009, p. 16), "como finalidade da Contabilidade Aplicada ao Setor Público oferecer à sociedade, de maneira transparente e acessível, o conhecimento amplo sobre a gestão da coisa pública". O Brasil está em processo de convergência da Contabilidade Aplicada no Setor Público (CASP) ao padrão internacional, pois vem ao encontro do desenvolvimento do país no cenário internacional. Para isso se concretizar foram elaboradas as Normas Brasileiras de Contabilidade Aplicadas ao Setor Público (NBCASP) pelo Conselho Federal de Contabilidade (CFC) em 2008, de acordo com o padrão internacional, bem como a elaboração do Manual de Contabilidade Aplicada ao Setor Público (MCASP), elaborado pela Secretaria do Tesouro Nacional (STN), que foi implementado no período de 2012 a 2014, na União, nos Estados, no Distrito Federal e nos Municípios.

Essa convergência parte da decisão do Brasil em adotar o padrão internacional, o que levou a elaboração das NBCASP pelo CFC no padrão das International Public Sector Accounting Standards (IPSAS), editadas pelo International Federation of Accountants (IFAC). Essas normas internacionais possuem objetivos que vem ao encontro de melhorar a qualidade dos relatórios financeiros do Setor Público, levando em consideração essa situação para uma avaliação de decisões de alocação de recursos realizados pelos gestores públicos, aumentando assim a transparência e a responsabilização. 
Para ocorrer o processo de convergência foi necessário a publicação da Portaria $\mathrm{n}^{\circ}$ 184/2008 pelo Ministério da Fazenda que determinou à Secretaria do Tesouro Nacional (STN) o desenvolvimento de ações para promover a convergência às Normas Internacionais de Contabilidade Aplicada ao Setor Público editadas pelo IFAC e às Normas Brasileiras de Contabilidade Aplicada ao Setor Público editadas pelo CFC (BRASIL, 2008).

O Conselho Federal de Contabilidade (CFC), órgão regulador das práticas contábeis no Brasil, a partir das normas contábeis do International Federation of Accountants (IFAC), a qual o Brasil é membro, reuniu um grupo de profissionais para a elaboração das Normas Brasileiras de Contabilidade Aplicada no Setor Público (NBCASP), em consonância nos fundamentos da International Public Sector Accounting Standards (IPSAS). As normas contábeis passaram, ainda, por audiências públicas para aprovação, logo após essa tramitação, no ano de 2008, surge então às primeiras dez Normas Brasileiras de Contabilidade Aplicadas ao Setor Público (NBCASP) e, em 2011, a décima primeira NBCASP.

Segundo Lima, Santana e Guedes (2009), as NBCASPs têm como objetivo fornecer um novo arcabouço conceitual para a Contabilidade Aplicada ao Setor Público (CASP) e contribuir para a uniformização de práticas e procedimentos contábeis, em virtude da dimensão e da diversidade da estrutura da Administração Pública Brasileira.

A CASP adotou um Plano de Contas Aplicado ao Setor Público (PCASP) de padrão único em todo o Estado brasileiro, na qual existe uma série de implementações decorrentes das normas que propiciarão uma melhor gestão e transparência da coisa pública por meio de informações geradas a partir da CASP. Os usuários dessas informações no Setor Público, além do governo, é o cidadão, a quem o governo é responsável em prestar contas, e também aqueles que são representantes desses cidadãos na esfera pública, os vereadores, deputados estaduais, deputados federais e senadores.

Conforme Iudícibus (2004 apud LIMA; SANTANA; GUEDES, 2009, p. 21), a informação contábil pode ser evidenciada de várias formas: demonstrações contábeis, notas explicativas e demonstrativos. Assim, a Contabilidade Aplicada ao Setor Público (CASP) é o instrumento utilizado pelos gestores públicos para fazer o controle dos recursos, orçamentários, financeiros e patrimoniais durante certo período.

Assim, este estudo tem por objetivo analisar a implementação da Contabilidade Aplicada ao Setor Público (CASP), abrangendo as Normas de Contabilidade Aplicada no Setor Público (NBCASP), o Plano de Contas Aplicada no Setor Público (PCASP) e as Demonstrações Contábeis Aplicadas no Setor Público (DCASP).

A fonte de coleta de dados foram os municípios do Conselho Regional de Desenvolvimento da Fronteira Oeste (COREDE-FO). O COREDE-FO representa um grupo das nove regiões funcionais de planejamento do Estado do Rio Grande do Sul, e agrupa treze municípios situados na região da Fronteira Oeste do Estado, que faz divisa com os países da Argentina e do Uruguai. O grupo de municípios que formam o COREDE-FO são os seguintes: Alegrete, Barra do Quaraí, Itacurubi, Itaqui, Maçambará, Manoel Viana, Quaraí, Rosário do Sul, Santa Margarida do Sul, Santana do Livramento, São Borja, São Gabriel e Uruguaiana. A regionalização dos COREDES foi definida através de um estudo de Desenvolvimento Regional Logístico do Estado do Rio do Sul rumo a 2015, baseados em critérios de homogeneidade econômica ambiental e social com adequação das variáveis correspondentes criando, assim, ações que possibilitem um desenvolvimento regional (RIO GRANDE DO SUL, 2012).

A atuação governamental e as finanças públicas estão ligadas a ação do Estado e estão obrigados ao cumprimento dos regulamentos e da aplicação da legislação (SILVA, 2009). 
Para isso, é necessário que os gestores públicos tenham total entendimento das mudanças trazidas pela alteração da legislação e de novos regulamentos em relação à Contabilidade Aplicada ao Setor Público (CASP), que envolve, principalmente, as demonstrações e demonstrativos contábeis, editados pela Secretaria do Tesouro Nacional (STN) e das normas editadas pelo Conselho Federal de Contabilidade (CFC).

\section{FUNDAMENTAÇÃO TEÓRICA}

\subsection{Contabilidade Aplicada ao Setor Público (CASP)}

Segundo Silva (2009, p. 11), a Contabilidade Aplicada ao Setor Público (CASP) é "um sistema integrador dos registros orçamentários, econômicos, financeiros e patrimoniais". Para que a citação descrita anteriormente se faça concreta é necessário o cumprimento dos Princípios de Contabilidade, das Normas Brasileiras de Contabilidade Aplicada ao Setor Público (NBCASP) e da legislação aplicada à Administração Pública.

A Lei $n^{\circ} 4.320 / 1964$ é a norma em vigor de maior importância no que diz respeito à definição de procedimentos específicos para a contabilidade das entidades do setor público. A mesma dispõe sobre normas gerais de direito financeiro para elaboração e controle dos orçamentos e balanços da União, dos Estados, do Distrito Federal e dos Municípios (BRASIL, 1964). Outra referência importante é a Lei Complementar $\mathrm{n}^{\circ} 101 / 2000$, a Lei de Responsabilidade Fiscal (LRF), que traz normas de finanças públicas voltadas à responsabilidade na gestão fiscal (BRASIL, 2000).

A partir da Lei $n^{\circ} 4.320 / 1964$ e da Lei Complementar $n^{\circ} 101 / 2000$, o momento mais significativo em relação à Contabilidade Aplicada ao Setor Público (CASP) foi no ano de 2008 com o reordenamento da CASP, conforme apresentado no Quadro 01.

Quadro 01 - Reordenamento da Contabilidade Aplicada ao Setor Público (CASP)

\begin{tabular}{|c|l|}
\hline Período & \multicolumn{1}{|c|}{ Especificação } \\
\hline 2008 & $\begin{array}{l}\text { Publicação das Normas Brasileiras de Contabilidade Aplicada ao Setor Público (NBCASP), pelo } \\
\text { Conselho Federal de Contabilidade (CFC), no padrão das International Public Setor Accounting } \\
\text { Standards (IPSAS). }\end{array}$ \\
\hline 2009 & $\begin{array}{l}\text { Elaboração do Manual de Contabilidade Aplicada no Setor Público (MCASP), pela Secretaria do } \\
\text { Tesouro Nacional (STN), trazendo a obrigatoriedade da adoção das práticas contábeis presentes nas } \\
\text { NBCASP. }\end{array}$ \\
\hline 2010 & $\begin{array}{l}\text { Vigência do MCASP após discussão com a classe contábil, Conselho Federal de Contabilidade (CFC) } \\
\text { e Conselhos Regionais de Contabilidade (CRCs). }\end{array}$ \\
\hline 2012 & $\begin{array}{l}\text { Aplicação da Contabilidade Aplicada no Setor Público (CASP) na União, nos Estados, no Distrito } \\
\text { Federal e Municípios de forma facultativa. } \\
\text { Federal de forma obrigatória. }\end{array}$ \\
\hline 2013 & \begin{tabular}{l} 
Aplicação da Contabilidade Aplicada no Setor Público (CASP) nos Municípios de forma obrigatória. \\
\hline
\end{tabular} \\
\hline
\end{tabular}

Fonte: Brasil (2012), adaptado pelos autores.

De acordo com a NBCASP 16.1, aprovada pela Resolução n ${ }^{\circ}$ 1.128/2008 do Conselho Federal de Contabilidade (CFC), o campo de aplicação da Contabilidade Aplicada no Setor Público são todas as entidades que pertencem ao Setor Público e essas devem observar as normas e as técnicas próprias da Contabilidade Aplicada ao Setor Público (CASP). É aplicada integralmente, as entidades governamentais, os serviços sociais e os conselhos profissionais; e parcialmente, as demais entidades do setor público, para garantir procedimentos suficientes de prestação de contas e instrumentalização do controle social.

GeECont, v.2, n. 2, Floriano-PI, Jul-Dez. 2015. 
Assim, será um desafio a aplicabilidade dessas novas normas para as organizações públicas, pois existem dois fatores identificados pelo Conselho Federal de Contabilidade (CFC), e pela Secretaria do Tesouro Nacional (STN) que podem ser um entrave para aplicação das normas das organizações públicas, que são um moderno sistema de tecnologia da informação que permita uma acessibilidade contínua; e capacitação e treinamento dos servidores e dos profissionais da área contábil.

\subsection{Normas Brasileiras de Contabilidade Aplicada no Setor Público (NBCASP)}

A Secretaria do Tesouro Nacional (STN), o Conselho Federal de Contabilidade (CFC) e os Conselhos Regionais de Contabilidade (CRCs) são os responsáveis pela aplicação dos procedimentos, das práticas, da elaboração e da divulgação das demonstrações contábeis, de forma torná-las convergentes com as International Public Setor Accounting Standards (IPSAS) nas entidades públicas.

As Normas Brasileiras de Contabilidade Aplicada ao Setor Público (NBCASP) editadas pelo Conselho Federal de Contabilidade (CFC) vêm trazer impactos não só na escrituração contábil dos fatos contábeis próprios do Setor Público, mas também, trarão reflexos comportamentais no cotidiano dos profissionais da contabilidade (AZEVEDO et al., 2009). No Quadro 02 apresenta-se as NBCASP.

Quadro 02 - Normas Técnicas

\begin{tabular}{|c|c|l|}
\hline NBCASP & Resolução & \multicolumn{1}{c|}{ Conteúdo } \\
\hline 16.1 & $1.128 / 2008$ & Conceituação, objeto e campo de aplicação. \\
\hline 16.2 & $1.129 / 2008$ & Patrimônio e Sistemas Contábeis. \\
\hline 16.3 & $1.130 / 2008$ & Planejamento e seus instrumentos sob o enfoque contábil. \\
\hline 16.4 & $1.131 / 2008$ & Transações no setor público. \\
\hline 16.5 & $1.132 / 2008$ & Registro contábil. \\
\hline 16.6 & $1.133 / 2008$ & Demonstrações Contábeis. \\
\hline 16.7 & $1.134 / 2008$ & Consolidação das Demonstrações Contábeis. \\
\hline 16.8 & $1.135 / 2008$ & Controle interno. \\
\hline 16.9 & $1.136 / 2008$ & Depreciação, Amortização e Exaustão. \\
\hline 16.10 & $1.137 / 2008$ & Avaliação e mensuração de Ativos e Passivos em entidades do Setor Público. \\
\hline 16.11 & $1.366 / 2011$ & Sistema de Informação de Custos do Setor Público. \\
\hline
\end{tabular}

Fonte: CFC, 2008, 2011, organizado pelos autores.

As NBCASP representam o instrumento no qual os gestores devem elevar a eficácia e efetividade da sua gestão proporcionando aplicabilidade das leis promovendo com maior transparência o planejamento e a responsabilidade da gestão fiscal. A aplicabilidade dentro do Setor Público facilitará controle do Patrimônio Público e maior transparência dos recursos aplicados pelo Poder Público.

\subsection{Plano de Contas Aplicado no Setor Público (PCASP)}

Com o enfoque nas mudanças ocorridas dentro da Contabilidade Aplicada ao Setor Público (CASP), o grupo Técnico de Padronização de Procedimentos Contábeis criado pela Portaria $n^{\circ}$ 136/2007 da Secretaria do Tesouro Nacional (STN) priorizou a elaboração de um Plano de Contas Aplicado ao Setor Público (PCASP) em conformidade com a Lei $\mathrm{n}^{\circ}$ 
4.320/1964, permitindo a consolidação das contas públicas conforme o art. 50, $2^{\circ}$, da Lei Complementar no 101/2000, a Lei de Responsabilidade Fiscal (LRF) (BRASIL, 2012).

Silva (2009, p. 96) define como Plano de Contas "o conjunto de contas obtido pela subordinação dos desdobramentos às subcontas, e destas contas que devem ser dispostas em ordem crescente de compreensão". Pode-se dizer que o Plano de Contas é o instrumento utilizado para proceder ao registro da escrituração contábil dos atos e fatos da Administração Pública, no qual reúne os registros desses que associam aos diferentes conjuntos de elementos patrimoniais com sua função específica (LIMA; CASTRO, 2009).

Para cada tipo de conjuntos idênticos pode se dar nomes diferentes conforme sua função dentro do patrimônio onde estiverem inseridos, como bens móveis e imóveis para o Estado, tudo pode ser considerado como instrumento de prestação real ou potencial de serviço (SILVA, 2009). A classificação das contas de acordo com a Teoria Patrimonialista está disposta da seguinte forma:

Contas Patrimoniais representam a situação estática, ou seja, o patrimônio, os elementos ativos e passivos, que são os bens, direitos, obrigações com terceiros e o patrimônio líquido.

Contas de resultado representam a situação dinâmica, as variações patrimoniais, ou seja, as contas que alteram o patrimônio líquido e demonstram o resultado do exercício (SILVA, 2009, p. 97).

Na Contabilidade Aplicada ao Setor Público (CASP), as contas estão classificadas quanto à natureza da informação, conforme apresentado no Quadro 03.

Quadro 03 - Natureza das Informações

\begin{tabular}{|l|l|}
\hline \multicolumn{1}{|c|}{ Natureza } & \multicolumn{1}{|c|}{ Especificação } \\
\hline Patrimonial & $\begin{array}{l}\text { Representadas pelas contas que integram o Ativo, Passivo, Patrimônio Líquido, } \\
\text { Variações Patrimoniais Diminutivas (VPD) e Variações Patrimoniais } \\
\text { Aumentativas (VPA). }\end{array}$ \\
\hline Orçamentária & $\begin{array}{l}\text { Representada pelas contas que registram aprovação e execução do planejamento e } \\
\text { orçamento, inclusive restos a pagar. }\end{array}$ \\
\hline Típica de Controle & $\begin{array}{l}\text { Representadas pelas contas não caracterizadas como contas patrimoniais, que } \\
\text { tenham função precípua de controle seja para fins de elaboração de informações } \\
\text { gerenciais específicas, acompanhamento de rotina, elaboração de procedimentos } \\
\text { de consistência contábil ou para registrar atos que não engajaram registros nas } \\
\text { contas patrimoniais, mas que potencialmente possam vir afetar o patrimônio. }\end{array}$ \\
\hline
\end{tabular}

Fonte: Brasil (2012), adaptado pelos autores.

O Plano de Contas Aplicado ao Setor Público (PCASP) está estruturado por níveis de desdobramento, sendo estes classificados e codificados de acordo com o apresentado no Quadro 04. 
Quadro 04 - Níveis da Estrutura do Plano de Contas

\begin{tabular}{|c|l|}
\hline Nível & \multicolumn{1}{c|}{ Classificação } \\
\hline $1^{\circ}$ Nível & Classe \\
\hline $2^{\circ}$ Nível & Grupo \\
\hline $3^{\circ}$ Nível & Subgrupo \\
\hline $4^{\circ}$ Nível & Título \\
\hline $5^{\circ}$ Nível & Subtítulo \\
\hline $6^{\circ}$ Nível & Item \\
\hline $7^{\circ}$ Nível & Subitem \\
\hline
\end{tabular}

Fonte: Lima e Castro (2009), adaptada pelos autores.

O Plano de Contas Aplicado ao Setor Público (PCASP) possui a seguinte estrutura básica, em nível de classes e grupos, conforme apresentado no Quadro 05.

Quadro 05 - Estrutura do Plano de Contas

\begin{tabular}{|c|c|c|c|}
\hline $\begin{array}{l}1.1 \\
1.2\end{array}$ & $\begin{array}{l}\text { Ativo } \\
\text { Ativo Circulante } \\
\text { Ativo Não Circulante }\end{array}$ & $\begin{array}{l}2 \\
2.1 \\
2.2 \\
2.3\end{array}$ & $\begin{array}{l}\text { Passivo } \\
\text { Passivo Circulante } \\
\text { Passivo Não Circulante } \\
\text { Patrimônio Líquido }\end{array}$ \\
\hline $\begin{array}{l}3 \\
3.1 \\
3.2\end{array}$ & $\begin{array}{l}\text { Variação Patrimonial Diminutiva } \\
\text { Pessoal e Encargos } \\
\text { Benefícios Previdenciários e Assistenciais } \\
\ldots \\
\text { Outras Variações Patrimoniais Diminutivas }\end{array}$ & $\begin{array}{l}4 \\
4.1\end{array}$ & $\begin{array}{l}\text { Variação Patrimonial Aumentativa } \\
\text { Impostos, Taxas e Contribuições de Melhoria } \\
\text { Contribuições } \\
\text {... } \\
\text { Outras Variações Patrimoniais Aumentativas }\end{array}$ \\
\hline $\begin{array}{l}5.1 \\
5.2 \\
5.3\end{array}$ & $\begin{array}{l}\text { Controles da Aprovação do Planejamento e } \\
\text { Orçamento } \\
\text { Planejamento Aprovado } \\
\text { Orçamento Aprovado } \\
\text { Inscrição de Restos a Pagar }\end{array}$ & $\begin{array}{l}6.1 \\
6.2 \\
6.3\end{array}$ & $\begin{array}{l}\text { Controles da Execução do Planejamento e } \\
\text { Orçamento } \\
\text { Execução de Planejamento } \\
\text { Execução do Orçamento } \\
\text { Execução de Restos a Pagar }\end{array}$ \\
\hline $\begin{array}{l}7 \\
7.1\end{array}$ & $\begin{array}{l}\text { Controles Devedores } \\
\text { Atos Potenciais } \\
\text { Administração Financeira } \\
\text { Divida Ativa } \\
\text { Riscos Fiscais } \\
\text { Custos } \\
\text { Outros Controles }\end{array}$ & $\begin{array}{l}8 \\
8.1 \\
8.2 \\
8.3\end{array}$ & $\begin{array}{l}\text { Controles Credores } \\
\text { Execução dos Atos Potenciais } \\
\text { Execução da Administração Financeira } \\
\text { Execução da Divida Ativa } \\
\text { Execução dos Riscos Fiscais } \\
\text { Apuração de Custos } \\
\text { Outros Controles }\end{array}$ \\
\hline
\end{tabular}

Fonte: BRASIL, 2012, adaptado pelos autores. 
Segundo Andrade et al. (2010, p.195), “o profissional de contabilidade deverá procurar adequar o Plano de Contas ao que determina a legislação pertinente e á realidade de cada entidade pública a que presta serviço", dado que cabe ao profissional da área estar envolvido com as mudanças do novo cenário contábil, fazendo destas mudanças um crescimento e aprendizado pessoal, agindo como sujeito de novas práticas dentro da Contabilidade Pública Aplicada ao Setor Público (CASP).

\subsection{Demonstrações Contábeis Aplicadas no Setor Público (DCASP)}

As Demonstrações Contábeis têm papel fundamental na Contabilidade Aplicada ao Setor Público, pois através dos dados evidenciados por ela se tem a transparência de resultados orçamentários, financeiro, econômico e patrimonial do Setor Público. "Em fase de regulamentação pela Lei n ${ }^{\circ}$ 4.320/1964 o processo estrutural das Demonstrações Contábeis do Setor Público brasileiro ainda está fundamentada no controle do Orçamento Público, tendo seus ativos e passivos estruturados para verificar déficits e superávits ao longo dos anos" (LIMA; CASTRO, 2009, p. 169).

A NBCASP 16.6, aprovada pela Resolução ${ }^{\circ} 1.133 / 2008$ alterada pela Resolução $n^{\circ}$ 1.268/2009 do Conselho Federal de Contabilidade (CFC), que trata das Demonstrações Contábeis do Setor Público (DCASP): Balanço Patrimonial; Balanço Orçamentário; Balanço Financeiro; Demonstrações das Variações Patrimoniais; Demonstrações dos Fluxos de Caixa; Demonstração das Mutações do Patrimônio Líquido e Demonstrações do Resultado Econômico. A Demonstração do Resultado Econômico é facultativa e as demais são obrigatórias. O Manual de Contabilidade Aplicada ao Setor Público (MCASP) alterou os anexos da Lei $\mathrm{n}^{\circ}$ 4.320/1964 em consonância com as demonstrações contábeis aprovada pela Resolução n 1.133/2008 e alterada pela Resolução nº 1.268/2009 do CFC.

\subsubsection{Balanço Orçamentário}

O art. 102, da Lei $n^{\circ}$ 4.320/1964 descreve que o Balanço Orçamentário apresentará as receitas e as despesas previstas em confronto com as realizadas. O Balanço Orçamentário, de acordo com a Resolução $n^{\circ} 1.268 / 2009$ do CFC, evidencia as receitas as despesas orçamentárias detalhadas em níveis relevantes de análise, confrontando o orçamento inicial e as suas atribuições com a execução, demonstrando o resultado orçamentário. Está estruturado de forma a evidenciar a integração entre planejamento e a execução orçamentária (CFC, 2012).

De acordo com o MCASP, o Balanço Orçamentário faz as evidências das receitas e das despesas orçamentárias, por categoria econômica, confronta o orçamento inicial, suas alterações com a execução, demonstra o resultado orçamentário e discrimina: a) as receitas por fonte; b) as despesas por grupo de natureza (BRASIL, 2012).

A análise do resultado orçamentário não permite obter conclusões acerca da eficiência na gestão fiscal. Para tal, existem as metas de resultado primário, nominal e montante da dívida consolidada líquida estabelecidas na Lei de Diretrizes Orçamentárias (LDO), exigidos pela Lei Complementar $n^{\circ}$ 101/2000 (LRF). A análise do Balanço Orçamentário gera informações complementares acerca da influência da execução orçamentária no atingimento dessas metas fiscais (BRASIL, 2012).

\subsubsection{Balanço Financeiro}

Segundo a Lei $\mathrm{n}^{\circ}$ 4.320/1964, art. 103, o Balanço Financeiro demonstra os ingressos (entradas) e dispêndios (saídas) de recursos financeiros a título de receita e despesas orçamentárias, bem como os recebimentos e pagamentos de natureza extraorçamentária, 
conjugados com os saldos de disponibilidade dos exercícios anterior e aqueles que passarão para o exercício seguinte.

O Balanço Financeiro, de acordo com a Resolução n ${ }^{\circ}$ 1.268/2009 do CFC, evidencia as receitas e despesas orçamentárias bem como os ingressos e dispêndios extraorçamentários, conjugados com saldos de caixa do exercício anterior e os que se transferem para o início do exercício seguinte (CFC, 2009).

De acordo com o MCASP, o Balanço Financeiro evidencia a movimentação financeira das entidades do setor público no período a que se refere, e discrimina: a) a receita orçamentária realizada por destinação de recurso (destinação vinculada e/ou destinação ordinária); b) a despesa orçamentária executada por destinação de recurso (destinação vinculada e/ou destinação ordinária); c) os recebimentos e os pagamentos extraorçamentários; d) as transferências financeiras decorrentes, ou não, da execução orçamentária; e) o saldo inicial e o saldo final em espécie (BRASIL, 2012).

\subsubsection{Balanço Patrimonial}

De acordo com a Lei $\mathrm{n}^{\mathrm{o}} 4.320 / 1964$, art. 105, no Balanço Patrimonial estarão demonstrados os Ativos Financeiro e Permanente, os Passivos Financeiros e Permanentes, o saldo Patrimonial e as Contas de Compensação. Os Ativos e Passivos Financeiros independem de autorização orçamentária para suas realizações, Ativo e Passivo Permanente (Não Financeiro) dependem de autorização orçamentária para suas realizações. As Contas de Compensação apenas correspondem aos atos potenciais (contratos convênios, garantias, etc.).

A Resolução $n^{\circ} 1.133 / 2008$, alterada pela Resolução $n^{\circ}$ 1.268/2009 do CFC, confere enfoque patrimonial ao Balanço Patrimonial e promove a convergência às normas internacionais de contabilidade às normas brasileiras de contabilidade, incluindo a legislação societária à Lei nº 6.404/1976 e suas alterações.

De acordo com as Resoluções mencionadas: a) Ativo: compreende as disponibilidades, os direitos e os bens, tangíveis ou intangíveis adquiridos, formados, produzidos, recebidos, mantidos ou utilizados pelo setor público, que seja portador ou represente um fluxo de benefícios, presente ou futuro, inerentes à prestação de serviços públicos; b) Passivo: compreende as obrigações assumidas pelas entidades do setor público para consecução dos serviços públicos ou mantidas na condição de fiel depositário, bem como as provisões; c) Patrimônio Líquido: é o valor residual dos ativos da entidade depois de deduzidos todos seus passivos; d) Contas de Compensação: compreende os atos que possam vir a afetar o patrimônio. Ainda, de acordo com as Resoluções mencionadas, no Balanço Patrimonial, o Ativo e o Passivo dividem-se em Circulante e Não Circulante.

De acordo com o MCASP, deve ser elaborado, como anexo o Demonstrativo do Superávit Financeiro apurado no Balanço Patrimonial do exercício anterior. De acordo com a Lei ${ }^{\circ}$ 4.320/1964, art. 43, esse demonstrativo mostra o superávit financeiro que é a diferença positiva entre o ativo e o passivo financeiro, conjugando-se, ainda, os saldos dos créditos, adicionais transferidos e as operações de crédito a eles vinculadas, que é uma das fontes para abertura de crédito adicional (BRASIL, 2012).

\subsubsection{Demonstrações das Variações Patrimoniais}

A Demonstração das Variações Patrimoniais (DVP) evidencia as alterações verificadas no Patrimônio durante o exercício financeiro, resultante ou independente da execução orçamentária, e indica o resultado patrimonial do exercício, segundo o art. 104, da Lei $\mathrm{n}^{\circ} 4.320 / 1964$. 
Segundo a Resolução $\mathrm{n}^{\circ}$ 1.268/2009 do CFC, a Demonstração das Variações Patrimoniais (DVP) evidencia as variações qualitativas decorrentes da execução orçamentária; as variações quantitativas são decorrentes de transação no Setor Público que aumentam ou diminuem o patrimônio líquido; as variações qualitativas são decorrentes de transações no setor que alteram a composição dos elementos patrimoniais sem afetar o patrimônio líquido.

De acordo com o MCASP, para fins de apresentação na DVP, as variações devem ser segregadas em quantitativas e qualitativas. O resultado patrimonial do período é apurado pelo confronto entre as variações quantitativas aumentativas e diminutivas (BRASIL, 2012).

\subsubsection{Demonstrações dos Fluxos de Caixa}

A Demonstração dos Fluxos de Caixa (DFC) tem o objetivo de contribuir para transparência da Gestão Pública, pois permite um melhor gerenciamento e controle financeiro das entidades do setor público. As informações dos fluxos de caixa são úteis para proporcionar aos usuários da informação contábil instrumento para avaliar a capacidade da entidade gerar caixa e equivalentes de caixa, bem como suas necessidades de liquidez. A DFC permite aos usuários projetar cenários de fluxos futuros de caixa e elaborar análise sobre eventuais mudanças em torno da capacidade de manutenção do regular financiamento dos serviços públicos (BRASIL, 2012).

De acordo com o MCASP, a Demonstração dos Fluxos de Caixa (DFC) deve ser elaborada pelo método direto evidenciar as movimentações havidas no caixa e seus equivalentes, nos seguintes fluxos: a) das operações: compreende os ingressos, inclusive decorrentes de receitas originárias e derivadas, e os desembolsos relacionados com a ação pública e os demais fluxos que não se qualificam como de investimento ou financiamento; b) dos investimentos: inclui os recursos relacionados à aquisição e à alienação de ativo não circulante, bem como recebimentos em dinheiro por liquidação de adiantamentos ou amortização de empréstimos concedidos e outras operações da mesma natureza; c) dos financiamentos: inclui os recursos relacionados à captação e à amortização de empréstimos e financiamentos (BRASIL, 2012).

\subsubsection{Demonstração das Mutações do Patrimônio Líquido}

A Demonstração das Mutações do Patrimônio Líquida (DMPL) da entidade deve apresentar a demonstração das mutações ocorridas no Patrimônio Líquido. A DMPL objetiva demonstrar: a) o déficit ou superávit patrimonial do período; b) cada mutação no patrimônio líquido reconhecida diretamente no mesmo; c) o efeito decorrente da mudança nos critérios contábeis e os efeitos decorrentes da ratificação de erros cometidos em exercícios anteriores; e d) as contribuições dos proprietários e distribuições recebidas por eles como proprietários (BRASIL, 2012).

\subsubsection{Demonstração do Resultado Econômico}

De acordo com a Resolução $\mathrm{n}^{\circ} 1.133 / 2008$ do CFC, a Demonstração do Resultado Econômico (DRE) evidencia o resultado econômico de ações do setor público. A DRE deve ser elaborada considerando sua interligação com o sistema de custos e apresentada na forma dedutiva, pelo menos, a seguinte estrutura: a) receita econômica dos serviços prestados e dos bens ou dos produtos fornecidos; b) custos e despesa identificados com a execução da ação pública; c) resultado econômico apurado.

De acordo com o MCASP, editado pela STN, a receita econômica é o valor apurado a partir de benefícios gerados à sociedade pela ação pública, obtido por meio da multiplicação da quantidade de serviços prestados, bens ou produtos, pelo custo de oportunidade. Custo de oportunidades é o valor que seria desembolsado na alternativa desprezada de menor valor 
entre aquelas consideradas possíveis para execução da ação pública. O resultado econômico é a demonstração apresentada pela norma que tem como objetivo passar informação gerencial ao gestor possibilitando a comparação do custo de oportunidade de atividades desenvolvidas na organização com as receitas que seriam auferidas caso a entidade cobrasse por serviços prestados (BRASIL, 2012).

\section{PROCEDIMENTOS METODOLÓGICOS}

A presente pesquisa caracteriza-se como descritiva e qualitativa. A pesquisa foi realizada nos municípios que compõem o COREDE-FO que são num total de 13 (treze): Alegrete, Barra do Quarai, Itacurubi, Itaqui, Maçambará, Manoel Viana, Quarai, Rosário do Sul, Santa Margarida do Sul, Sant'Ana do Livramento, São Borja, São Gabriel e Uruguaiana, no Estado do Rio Grande do Sul. O grupo escolhido para presente pesquisa foi um fator determinante para o estudo da Região, pois os municípios que compõem uma das nove regiões funcionais dos COREDEs, no caso o COREDE-FO indicam municípios com características semelhantes no que se referem às desigualdades socioeconômicas.

O estudo foi realizado com base nas Normas Brasileiras de Contabilidade Aplicada ao Setor Público (NBCASP), editadas pelo Conselho Federal de Contabilidade (CFC), que são editadas a partir dos Pronunciamentos Técnicos emitidos pelo Comitê de Pronunciamentos Contábeis (CPC) e pelo Manual de Contabilidade Aplicada ao Setor Público (MCASP), elaborado pela Secretaria do Tesouro Nacional (STN). Os instrumentos de coleta de dados foram a análise documental e o questionário, elaborado com 10 (dez) perguntas abertas e aplicado aos servidores responsáveis pela Contabilidade Aplicada ao Setor Público (CASP) nos municípios do COREDE-FO.

A aplicação dos questionários deu-se de forma indireta, sem o contato com os respondentes, e foram utilizados os endereços eletrônicos para o envio destes. Do total de 13 (treze) questionários enviados, 07 (sete) retornaram respondidos, correspondendo a $55 \%$. Os respondentes foram identificados da seguinte forma: A, B, C, D, E, F, G.

Para atingir os objetivos da pesquisa: a pergunta 01 refere-se diretamente ao respondente; as questões 02, 03 e 04 estão relacionadas ao NBCASP; as questões 05 e 06 abrangem PCASP; as questões 07 e 08 abrangem a DCASP; as questões 09 e 10 correspondem a análise que todo esse processo irá causar no município no qual o respondente atua. Desta forma, passa-se a análise das respostas e documental.

\section{ANÁLISE DOS DADOS}

Os respondentes, responsáveis da área de contabilidade das prefeituras municipais trabalham há, em média, 13 (treze) anos com a contabilidade aplicada ao setor público. Este dado demonstra que os respondentes já possuem experiência suficiente tanto na área contábil quanto no setor público.

Em relação ao processo de convergência da Contabilidade Aplicada ao Setor Público, todos os respondentes afirmam possuir conhecimento. Entretanto, as fontes de informação para atualização, em relação às mudanças, são múltiplas. Eles destacam como fonte de atualização a própria legislação, o Conselho Regional de Contabilidade e as consultorias para o setor público. Apesar do conhecimento do assunto, através da realização de cursos sobre o 
tema da Convergência, os respondentes têm dúvidas de como será implementado o processo de convergência da Contabilidade Aplicada ao Setor Público nos Municípios.

Os respondentes afirmam, em sua maioria, que são favoráveis à aplicação das Normas Internacionais Aplicadas ao Setor Público nas entidades da Administração Pública brasileira. Entre os benefícios da adequação das Normas Brasileiras de Contabilidade, os responsáveis pelas áreas de contabilidade das prefeituras pesquisadas destacam que a aplicabilidade das normas no Setor Público faz com que o gestor público tenha mais responsabilidade e transparência no gerenciamento dos bens públicos quando aplicado às NBCASP. Entretanto, há uma preocupação, por parte dos respondentes, com a sua operacionalização, no âmbito municipal. A operacionalização das novas normas gera grande dependência de sistemas de informação, e estes são, em sua maioria, contratados através de empresas de tecnologia e não desenvolvidas pelos próprios municípios. O Conselho Federal de Contabilidade (CFC) e a Secretaria do Tesouro Nacional (STN) já haviam identificado os sistemas de tecnologia da informação como um potencial entrave para aplicação das normas nas organizações públicas.

Os responsáveis pelas áreas de contabilidade afirmam que não há suporte necessário para as mudanças que estão ocorrendo na contabilidade aplicada ao setor público para os municípios. Destaca-se que a estrutura organizacional é um fator preocupante, pois essa interação deve envolver não somente o setor contábil, mas também vários setores dentro da Administração Pública e para isso deve haver um comprometimento do gestor público para com os envolvidos nesse processo. Conforme já descrito no aporte teórico, os órgãos competentes, como STN e CFC, consideram que, além do sistema de tecnologia da informação, a capacitação e o treinamento de servidores e profissionais da área contábil podem ser considerados outro entrave para aplicação das novas NBCASP.

Os respondentes não tiveram um treinamento específico sobre como atuarem com o Plano de Contas e o conhecimento que possuem não dá suporte para aplicabilidade de imediato, porém o Plano de Contas de padrão único deve ser inserido nos municípios até 2013, o qual foi prorrogado para 2014 pela Secretaria do Tesouro Nacional, por meio da Portaria $\mathrm{n}^{\circ}$ 753/2012 (BRASIL, 2012).

Em relação à aplicação da Teoria Patrimonialista na contabilidade do Setor Público, alguns respondentes mostram-se resistentes, dado que pensam a contabilidade como mera execução do orçamento e controle das finanças públicas. Entretanto, a maioria dos respondentes entende que a Teoria Patrimonialista agrega benefícios na geração da informação para os gestores públicos e demais usuários destas informações. Para o Respondente G:

\begin{abstract}
a nova contabilidade aplicada ao setor público está resgatando e dando a devida importância para os ativos patrimoniais. O objetivo maior destas mudanças é adequar a contabilidade pública brasileira às normas internacionais de contabilidade aplicadas ao setor público, implicando, dentre outros fatos, a adoção completa do regime de competência em substituição ao regime misto adotado, até então, por este melhor refletir a situação patrimonial. Com isto buscar uma evidenciação correta do seu Patrimônio, como um ponto de partida coerente e atualizado.
\end{abstract}

Em relação ao uso das Demonstrações Contábeis no processo de tomada de decisões e na prestação de contas pelos gestores públicos, alguns respondentes afirmam que os gestores não estão preparados para fazer uso destas informações. Para o Respondente A, "os nossos gestores não estão preparados para utilizarem as Demonstrações Contábeis como ferramenta de gestão". No caso do gestor não possuir conhecimento para a análise das informações contábeis, se faz necessário que ele seja assessorado pelos servidores da área contábil, como reforça o Respondente C. "É inegável que as demonstrações contábeis têm papel importante em tomadas de decisões gerenciais. $\mathrm{O}$ ente público clama por um bom gerente. Não há mais 
espaço para amadores na gestão de políticas públicas. O ente público deve ter profissionais gabaritados na leitura e interpretação de balanços".

Assim, as Demonstrações Contábeis, na percepção dos respondentes, geram informações para contribuir com a gestão das organizações públicas desde que utilizada por profissionais e gestores capacitados para a tomada de decisão.

Um dos objetivos do processo de convergência é ampliar a transparência do gasto público através da publicização das Demonstrações Contábeis capaz de refletir a real aplicação do recurso público. Os respondentes afirmam que a convergência contribui para o acesso à informação por parte da população. Entretanto, há uma preocupação dos profissionais de contabilidade com a linguagem em que são elaboradas estas informações.

A contabilidade tem papel importante na transparência; e o sacrifício que é imputado aos profissionais operantes merece objetividade. Por enquanto, o acesso a todos vai ficar dependendo de pessoal tradutor que possa postar em linguagem popular a explicação junto às demonstrações na transparência (RESPONDENTE C).

Assim, as Demonstrações Contábeis são uma ferramenta importante para o gestor evidenciar a transparência e gerenciamento dos recursos públicos do município para a população. A transparência, a clareza e a objetividade na publicação dos demonstrativos estão evidenciadas nas Normas Brasileiras de Contabilidade Aplicada ao Setor Público (NBCASP) (BRASIL, 2012).

Os responsáveis pela área de contabilidade consideram que o plano de contas de padrão único, além de padronizar os registros contábeis nas esferas municipal, estadual e federal, melhora as informações da prestação de contas, pois estrutura as informações de natureza patrimonial, orçamentária e típica de controle, permitindo uma melhor visualização do conjunto de informações geradas no setor público. Para o respondente F, "o novo modelo é de mais fácil acesso, permitindo uma melhor visão da gestão diante dos recursos envolvidos". Destaca-se, ainda, que o plano de contas de padrão único contribui para o acesso à informação e controle dos recursos públicos pela sociedade.

Com o novo modelo haverá uma padronização nas três esferas de governo, o qual facilitará o controle orçamentário e financeiro dos órgãos públicos, assim facilitando o entendimento, ou seja, a leitura das demonstrações contábeis pelo cidadão, cumprindo com a legislação que determina a transparência da gestão pública. Este instrumento de informações de natureza orçamentária, financeira, econômica e física do patrimônio público servirá de apoio à prestação de contas da gestão, á tomada de decisão, e à instrumentalização ao controle social (RESPONDENTE E).

Por fim, a STN estabeleceu um cronograma para a implementação da Nova Contabilidade Aplicada ao Setor Público até 2013, ano que abrangia a implementação nos municípios, prazo prorrogado para 2014, em função da dificuldade de implementação do plano de contas de padrão único por parte dos municípios. Para responsáveis pela área de contabilidade, o processo de implantação das mudanças na contabilidade pública depende das condições disponibilizadas pelos gestores públicos, como afirma o respondente $\mathrm{C}$.

O tempo que leva para a implantação plena depende da estrutura da entidade pública. Em municípios pequenos o profissional contábil faz diversas tarefas devido à carência de pessoal. Essa situação levanta questionamentos quanto à possibilidade de todos os fatos serem contemplados por registro contábil. Nesse processo de mudança a contabilidade pública vai registrar movimentações financeiras; de reconhecimento patrimonial de receitas e despesas; de contratos e demais atos potenciais; de controle de disponibilidade de recursos; de alterações no PPA; de contabilidade de custos; e demais peculiaridades. Isso vai requerer uma estrutura condizente com o porte e movimentação do ente público (RESPONDENTE C). 
Os respondentes consideram que o prazo depende de um esforço conjunto das áreas envolvidas na implementação deste processo, bem como, do apoio da gestão dos municípios, das entidades de classe, dos profissionais da área, todos focados na aplicação e no cumprimento das NBCASP. A aplicação desta traz impactos profundos não só na escrituração e nos fatos contábeis, mas também reflexos comportamentais no cotidiano dos contabilistas (AZEVEDO et al., 2009).

\section{CONSIDERAÇÕES FINAIS}

A pesquisa teve como objetivo principal analisar a implantação da Contabilidade Aplicada ao Setor Público (CASP). A análise do processo das mudanças trazidas pelas Normas Brasileiras de Contabilidade Aplicada ao Setor Público (NBCASP) foi realizada a partir de análise documental e questionários aplicados com os responsáveis pela contabilidade nas prefeituras que fazem parte do COREDE-FO quanto à implementação das NBCASP, o conhecimento do Plano de Contas Aplicado ao Setor Público (PCASP) e das Demonstrações Contábeis Aplicadas ao Setor Público (DCASP).

As análises evidenciam que os respondentes possuem conhecimento sobre o processo de convergência e acreditam, na sua maioria, que essas mudanças contribuem para o aumento da transparência na aplicação dos recursos e gestão do patrimônio nos municípios. Eles acreditam que o tempo de implementação desse processo depende da estrutura que será disponibilizada, dado que nos municípios pequenos, os profissionais de contabilidade acabam atuando em diversas áreas.

A partir das análises, evidencia-se uma preocupação por parte dos profissionais que atuam na área contábil dos municípios pesquisados em relação à implementação das NBCASP e do plano de contas de padrão único que tem dependência dos sistemas de informação, fato que corrobora com a preocupação da STN mencionada no aporte teórico, além da capacitação e treinamento dos servidores. No entanto, entende-se que os órgãos competentes para essa capacitação e treinamento sejam, principalmente, o Conselho Regional de Contabilidade do Rio Grande do SUL (CRCRS), juntamente com o Conselho Federal de Contabilidade (CFC) e da própria Secretaria do Tesouro Nacional (STN).

Ainda, a partir das análises, evidencia-se a importância da publicação das Demonstrações Contábeis para a promoção da transparência das informações, muito embora a linguagem das informações possa não ser suficientemente clara para toda população.

Sugere-se, a partir deste estudo, que futuras pesquisas avaliem a implementação da Nova Contabilidade Aplicada ao Setor Público para analisar o resultado da aplicação prática das Normas Brasileiras de Contabilidade, em especial nos municípios brasileiros, para aferir a real contribuição para a gestão pública e para o acesso da sociedade brasileira às informações referentes à aplicação dos recursos públicos e a gestão do patrimônio público.

\section{Referências}

ANDRADE, Nilton de Aquino et al. Planejamento governamental para municípios: plano plurianual, lei de diretrizes orçamentárias e lei orçamentária anual. 3. ed. São Paulo: Atlas, 2010.

AZEVEDO, R. R. de, et at. (org.), Normas Brasileiras de Contabilidade Aplicada 
ao Setor Público. Nova Letra, 2009.

BRASIL. Lei no 4.320, de 17 de Março de 1964, Casa Civil. Estatui Normas Gerais de Direito Financeiro para elaboração e Controle dos Orçamentos e Balanços da União, Estados, Distrito Federal e Municípios. Diário Oficial da República Federativa do Brasil. Brasília, DF, 17 de março 1964. Disponível em: <www.planalto.gov.br/ccivil_03/Leis/L4320.htm>.Acesso 26 mai. 2012.

BRASIL. Lei n ${ }^{\circ}$ 6.404, de 15 de dezembro de 1976. Estatui normas para as Sociedades por Ações. Diário Oficial da República Federativa do Brasil. Brasília, DF, 15 de dezembro de 1976. Disponível em: <http://www.planalto.gov.br/ccivil_03/leis/16404consol.htm>. Acesso em: 02 jun. 2014.

BRASIL. Lei Complementar $\mathbf{n}^{\mathbf{0}}$ 101, de 04 de maio de 2000. Lei de Responsabilidade Fiscal (LRF). Estabelece normas de finanças públicas voltadas para a responsabilidade na gestão fiscal e dá outras providências. Diário Oficial da República Federativa do Brasil. Brasília, DF, 04 de maio de 2000. Disponível em: <http://www.planalto.gov.br/ccivil_03/leis/lcp/lcp101.htm>. Acesso em: 20 abr. 2012.

BRASIL. Portaria $\mathbf{n}^{\mathbf{0}} \mathbf{1 8 4}$, de 25 de agosto de 2008. Dispõe sobre as diretrizes a serem observadas no setor público (pelos entes públicos) quanto aos prodecimentos, práticas, elaboração e divulgação das demonstrações contábeis, de forma a torná-los convergentes com as Normas Internacionais de Contabilidade Aplicadas ao Setor Público. Diário Oficial da República Federativa do Brasil. Brasília, DF, 26 de agosto de 2008. Disponível em: <http://www.fazenda.gov.br/institucional/legislacao/2008/portaria184>. Acesso em: 10 mar. 2013.

BRASIL. Portaria n $\mathbf{n}^{\mathbf{0}} \mathbf{7 5 3}$, de 21 de dezembro de 2012. Altera a Portaria $\mathrm{n}^{\mathbf{0}}$ 437, de 12 de julho de 2012, e Portaria $\mathrm{n}^{\circ}$ 828, de 14 de dezembro de 2011, e dá outras providências. Diário Oficial da República Federativa do Brasil. Brasília, DF, 26 de dezembro de2012. Disponível em:<https://www.tesouro.fazenda.gov.br/images/arquivos/artigos/Portaria_STN_7532012_Altera_Portarias_STN_437_2012_828-2011.pdf>. Acesso em: 10 mar. 2013.

BRASIL. Secretaria do Tesouro Nacional (STN). Manual de Contabilidade Aplicada ao Setor Público. Procedimentos Contábeis Orçamentários, Ministério da Fazenda - Secretaria do Tesouro Nacional, Ministério do Planejamento, Orçamento e Gestão Secretaria de Orçamento Federal. 4. ed. Brasília: STN, 2012.

CONSELHO FEDERAL DE CONTABILIDADE (CFC). Resolução n ${ }^{\circ} \mathbf{1 1 2 8}$, de 21 de novembro de 2008. Aprova a NBC T 16.1- Conceituação, Objeto e Campo de Aplicação. Disponível em:

<http://www2.cfc.org.br/sisweb/sre/detalhes_sre.aspx?Codigo=2008/001128>. Acesso em: 28 mai. 2014.

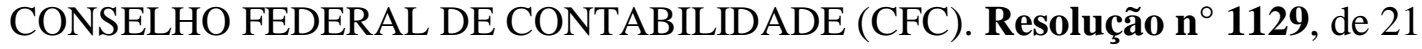
de novembro de 2008. Aprova a NBC T 16.2 - Patrimônio e Sistemas Contábeis. Disponível em: <http://www2.cfc.org.br/sisweb/sre/detalhes_sre.aspx?Codigo=2008/001129>. Acesso em: 28 mai. 2014.

CONSELHO FEDERAL DE CONTABILIDADE (CFC). Resolução n ${ }^{\circ} \mathbf{1 1 3 0}$, de 21 de novembro de 2008. Aprova a NBC T 16.3 - Planejamento e seus Instrumentos sob o Enfoque Contábil. Disponível em:

<http://www2.cfc.org.br/sisweb/sre/detalhes_sre.aspx?Codigo=2008/001130>. Acesso em: 28 mai. 2014. 
CONSELHO FEDERAL DE CONTABILIDADE (CFC). Resolução n 1131, de 21 de novembro de 2008. Aprova a NBC T 16. 4- Transações no Setor Público. Disponível em:

<http://www2.cfc.org.br/sisweb/sre/detalhes_sre.aspx?Codigo=2008/001131>. Acesso em: 28 mai. 2014.

CONSELHO FEDERAL DE CONTABILIDADE (CFC). Resolução n ${ }^{\circ} \mathbf{1 1 3 2}$, de 21 de novembro de 2008. Aprova a NBC T 16.5 - Registro Contábil. Disponível em: <http://www2.cfc.org.br/sisweb/sre/detalhes_sre.aspx?Codigo=2008/001132>. Acesso em: 28 mai. 2014.

CONSELHO FEDERAL DE CONTABILIDADE (CFC). Resolução n ${ }^{\circ}$ 1133, de 21 de novembro de 2008. Aprova a NBC T 16.6 - Demonstrações Contábeis. Disponível em: $<$ http://www2.cfc.org.br/sisweb/sre/detalhes_sre.aspx?Codigo=2008/001133>. Acesso em: 28 mai. 2014.

CONSELHO FEDERAL DE CONTABILIDADE (CFC). Resolução $\mathbf{n}^{\circ} \mathbf{1 1 3 4}$, de 21 de novembro de 2008. Aprova a NBC T 16.7- Aprova a NBC T 16.7 - Consolidação das Demonstrações Contábeis. Disponível em:

<http://www2.cfc.org.br/sisweb/sre/detalhes_sre.aspx?Codigo=2008/001134>. Acesso em: 28 mai. 2014.

CONSELHO FEDERAL DE CONTABILIDADE (CFC). Resolução $\mathbf{n}^{\circ} \mathbf{1 1 3 5}$, de 21 de novembro de 2008. Aprova a NBC T 16.8 - Controle Interno. Disponível em: <http://www2.cfc.org.br/sisweb/sre/detalhes_sre.aspx?Codigo=2008/001135>. Acesso em: 28 mai. 2014.

CONSELHO FEDERAL DE CONTABILIDADE (CFC). Resolução n ${ }^{\circ}$ 1136, de 21 de novembro de 2008. Aprova a NBC T 16.9 - Depreciação, Amortização e Exaustão. Disponível em: <http://www2.cfc.org.br/sisweb/sre/detalhes_sre.aspx?Codigo=2008/001136>. Acesso em: 28 mai. 2014.

CONSELHO FEDERAL DE CONTABILIDADE (CFC). Resolução n 1137, de 21 de novembro de 2008. Aprovar a NBC T 16.10 - Avaliação e Mensuração de Ativos e Passivos em Entidades do Setor Público. Disponível em: $<$ http://www2.cfc.org.br/sisweb/sre/detalhes_sre.aspx?Codigo=2008/001137>. Acesso em: 28 mai. 2014.

CONSELHO FEDERAL DE CONTABILIDADE (CFC). Resolução n $\mathbf{1 3 6}^{\circ}, 25$ de novembro de 2011. Aprova a NBC T 16.11 - Sistema de Informação de Custos do Setor Público. Disponível em:

<http://www2.cfc.org.br/sisweb/sre/detalhes_sre.aspx?Codigo=2011/001366>. Acesso em: 28 mai. 2014.

CONSELHO FEDERAL DE CONTABILIDADE (CFC). Resolução CFC n. ${ }^{\circ} \mathbf{1 2 6 8}$, de 21 de dezembro de 2009. Altera, inclui e exclui itens das NBC T 16.1, 16.2 e 16.6 que tratam das Normas Brasileiras de Contabilidade Técnicas aplicadas ao Setor Público e dá outras providências. Disponível em:

$<$ http://www.cfc.org.br/sisweb/sre/detalhes_sre.aspx?Codigo=2009/001268>. Acesso em: 15 abr. 2014. 2010.

GIL, Antonio Carlos. Como Elaborar Projetos de Pesquisa. 5. ed. São Paulo: Atlas, 
LIMA, Diana Vaz de; CASTRO, Robinson Gonçalves de. Contabilidade Pública: integrando União, Estados e Municípios (SIAFI e SIAFEM). 3. ed. São Paulo: Atlas, 2009.

LIMA, Diana Vaz de; SANTANA, Cláudio Moreira; GUEDES, Marianne Antunes. As Normas Brasileiras de Contabilidade Aplicadas ao Setor Público e a Legislação Contábil Pública Brasileira: uma análise comparativa à luz da teoria contábil. Revista Contabilidade, Gestão e Governança, v. 12, n. 2, p. 15-23, mai/ago 2009.

RIO GRANDE DO SUL. Secretaria de Planejamento, Gestão e Participação Cidadã/Departamento de Planejamento Governamental. Regiões Funcionais de Planejamento e COREDEs. Porto Alegre, 21 de abril de 2012. Disponível em: <http://www.seplag.rs.gov.br/conteudo_puro.asp?ta=1\&modo_exibicao=LISTA\&cod_menu= 492\&cod_menu_pai=453\&cod_tipo_conteudo=5>. Acessado em: 21 abr. 2012.

SILVA, Lino Martins da. Contabilidade Governamental: um enfoque administrativo da nova contabilidade pública. 8. ed. São Paulo: Atlas, 2009. 